\title{
ESTUDO DA ESTABILIDADE TÉRMICA DE CATALISADORES DESATIVADOS REGENERADOS
}

\author{
A. B. C. DENIZ ${ }^{1}$, R. B. G. VALT ${ }^{2}$, L. S. SANCHES ${ }^{3}$, M. J. J. S PONTE ${ }^{4}$, H. A. PONTE ${ }^{5}$ \\ ${ }^{1}$ Universidade Federal do Paraná \\ ${ }^{2}$ Universidade Federal do Paraná \\ ${ }^{3}$ Universidade Federal do Paraná \\ ${ }^{4}$ Universidade Federal do Paraná, Departamento de Engenharia Mecânica \\ ${ }^{5}$ Universidade Federal do Paraná, Departamento de Engenharia Química \\ E-mail para contato: amanda.broska@yahoo.com.br
}

\begin{abstract}
RESUMO - Os catalisadores residuais provenientes dos processos de craqueamento catalítico de petróleo têm motivado diversas pesquisas visando a diminuição de sua periculosidade. Neste trabalho, o catalisador desativado foi remediado com o emprego de soluções de citrato de sódio e ácido sulfúrico como eletrólitos, junto a aplicação de potencial de $11 \mathrm{~V}$ durante $48 \mathrm{~h}$, objetivando a remoção dos metais adsorvidos. Após este tratamento o material seco foi analisado em um equipamento TG/DTA para avaliar a decomposição térmica do catalisador antes e após o processo de remediação de modo a avaliar a fragilidade do material com relação ao aquecimento. Os resultados obtidos indicaram a ocorrência de um sinal endotérmico com dois picos de temperatura e um sinal exotérmico com um pico de temperatura, tanto para o material tratado quanto para o catalisador desativado. Deste modo, verificou-se que o processo de regeneração empregado não afetou a estabilidade térmica do material.
\end{abstract}

\section{INTRODUÇÃO}

Os processos de refino de petróleo vêm sendo constantemente aprimorados com objetivo de transformar frações pesadas do petróleo em frações mais leves e de maior valor agregado. Porém, devido a este avanço tecnológico, a indústria petroquímica tem gerado uma grande quantidade de resíduo. O resíduo que provém do processo de craqueamento catalítico de leito fluidizado $(F C C)$ é composto em sua íntegra pelo catalisador desativado que foi utilizado neste processo e que apresenta em sua composição química basicamente tetraedros de sílica e alumínio e uma quantidade apreciável de níquel e vanádio, oriundos do petróleo. Existe neste caso uma grande preocupação ambiental em diminuir a periculosidade do resíduo gerado, classificado hoje como Classe I. Uma das maneiras de diminuir a periculosidade deste material é removendo os metais adsorvidos no catalisador através da aplicação da técnica de remediação eletrocinética.

A remediação eletrocinética, também chamada de processamento eletrocinético do solo, eletromigração, descontaminação eletrocinética, ou eletrocorreção, pode ser usada para separar 
(extrair) metais e alguns tipos de resíduos orgânicos de solos saturados ou insaturados, lamas e sedimentos (Acar, 1995). No entanto, a aplicação desta metodologia para o tratamento de catalisadores de FCC desativados é inédita, tendo início com os estudos de Baptista (2005) do Grupo de Eletroquímica Aplicada da UFPR.

Em resumo aplica-se ao solo uma corrente direta de baixa intensidade ou uma diferença de potencial elétrico na ordem de poucos volts por centímetro mediante a introdução de placas de eletrodos (Baptista, 2005). Os contaminantes são então mobilizados na forma de espécies carregadas ou partículas, sendo removidos do sistema. Os principais fenômenos que comandam os processos eletrocinéticos são a eletromigração e a eletroosmose. Na eletromigração os íons carregados obedecem à Lei de Coulomb: “As partículas ou íons de carga positiva migram para o pólo negativo (cátodo) e moléculas ou íons de carga negativa vão para o pólo positivo (ânodo)”. Já a eletroosmose representa o movimento da fase líquida devido a uma diferença de potencial elétrico externo aplicado a uma fase sólida contínua que contém a fase líquida.

Uma vez que vários metais são removidos do catalisador, inclusive metais da estrutura da zeólita que o compõe, torna-se importante verificar se o processo de remediação eletrocinética provoca alguma variação na estabilidade térmica neste material. Esta estabilidade térmica pode ser avaliada através da Termogravimetria $(T G)$ e da Análise Térmica Diferencial $(D T A)$

Termogravimetria é a técnica na qual a mudança da massa de uma substância é medida em função da temperatura enquanto esta é submetida a uma programação controlada. Na análise térmica diferencial a temperatura da amostra é comparada a uma amostra inerte de referência, eliminando os efeitos da taxa de aquecimento e outros distúrbios externos que possam mudar a temperatura da amostra.

Ao longo do programa de aquecimento, as temperaturas da amostra e da referência se mantêm iguais até que ocorra alguma alteração física ou química na amostra. Se a reação for exotérmica a amostra irá liberar calor, ficando por um curto período de tempo com uma temperatura maior que a referência. Já se a reação for endotérmica, a temperatura da amostra será temporariamente menor que a referência. Deste modo, mudanças na amostra, fusão, solidificação, cristalização e decomposição são registradas sob a forma de picos.

Deste modo, o objetivo deste trabalho é verificar, através de análises de $T G$ e $D T A$, se o processo de remediação eletrocinético ao qual são submetidos os catalisadores de $F C C$ desativados provoca a desestabilização térmica do material.

\section{METODOLOGIA}

\subsection{Remediação Eletrocinética}

A Figura 1 apresenta o esquema utilizado para a execução dos experimentos de remediação eletrocinética. 


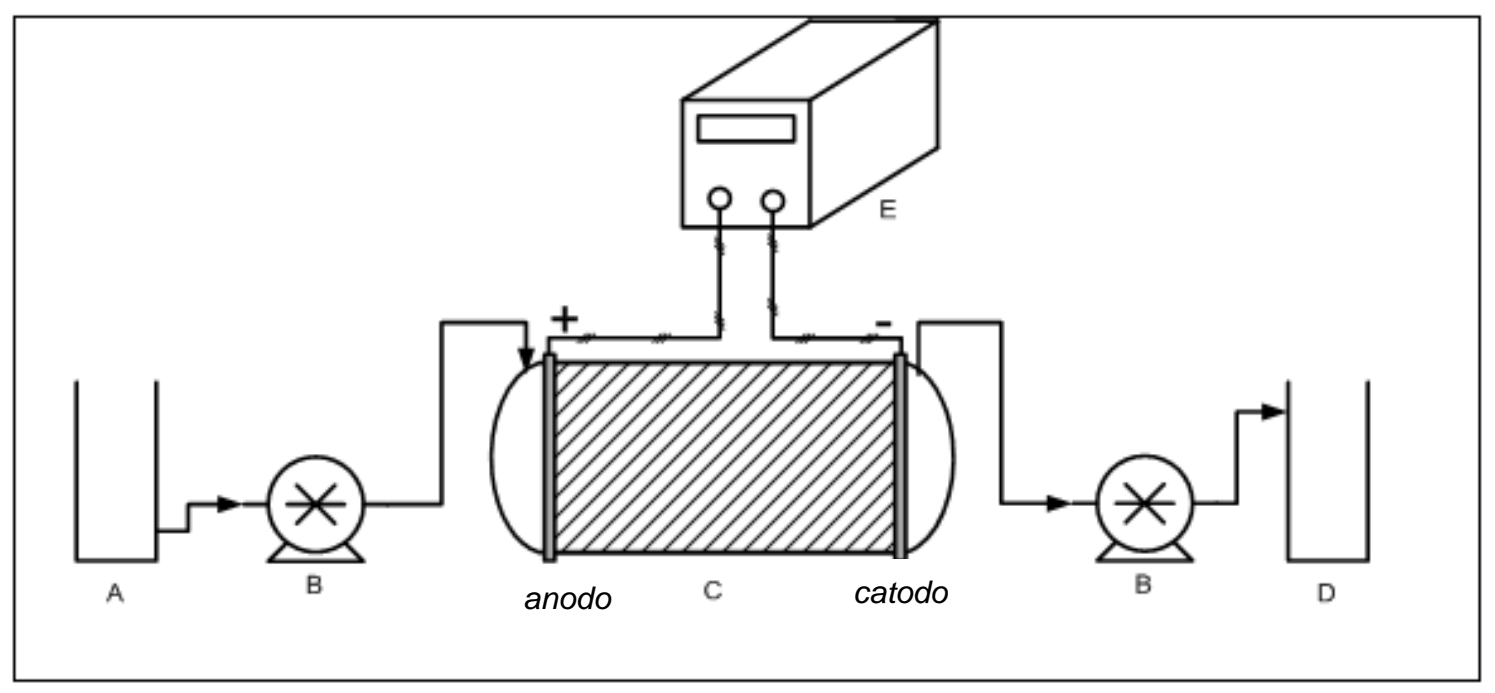

Figura 1- Esquema da instalação de remediação eletrocinética experimental.

(A: reservatório de eletrólito novo; B: bomba peristáltica; C: reator eletrocinético; D: reservatório de eletrólito contaminado; E: fonte de potencial).

Baseado em estudos anteriores realizados por Baptista (2005) e Creplive (2008), a melhor condição experimental para remoção de vanádio foi com lavagem ácida (eletrólito - solução de ácido sulfúrico) de concentração 1,0 mol/L. O catalisador ficou em repouso com eletrólito durante $24 \mathrm{~h}$. Em seguida, aplicou-se um gradiente de potencial elétrico de $11 \mathrm{~V}$ entre os eletrodos (anodo de $\mathrm{Ti} / \mathrm{Ir}-\mathrm{Ru}$ e catodo de $\mathrm{Pb}$ ), associado a bombeamento peristáltico de $100 \mathrm{~mL} / \mathrm{h}$ do eletrólito por 48 h. Decorrido este tempo foi bombeada água destilada para remoção do eletrólito e metais superficiais e procedeu-se à secagem do material em estufa a $45^{\circ} \mathrm{C}$ por $48 \mathrm{~h}$. O mesmo procedimento foi aplicado utilizando-se uma solução $0,5 \mathrm{~mol} / \mathrm{L}$ de citrato de sódio. $\mathrm{O}$ meio eletrolítico contendo o íon citrato foi selecionado devido ao fato deste ânion ter facilidade em complexar íons $\mathrm{Ni}$ e $\mathrm{V}$, tanto em meio alcalino quanto em meio ácido. O complexo de citrato mais íons apresenta estruturas distintas em $\mathrm{pH}=0$ e $\mathrm{pH}=8$, porém com mesmo poder de complexação. (Cruywagen, et al.,1995 e Sanches, et al., 2003). Neste estudo foi utilizado $\mathrm{pH}=8$.

\subsection{Análise de Metais}

Os teores de metais no catalisador após o tratamento por remediação eletrocinética foram determinados por Fluorescência de Raios-X (FRX).

Para os testes de FRX procedeu-se à preparação de pastilhas dos catalisadores. Pesou-se $7 \mathrm{~g}$ do catalisador moído adicionou-se $1,4 \mathrm{~g}$ de aglomerante. Homogeneizou-se a mistura de catalisador e aglomerante e prensou-se a mistura em uma prensa PFAFF com pressão de até $40 \mathrm{tf} / \mathrm{cm}^{2}$. A pastilha prensada foi então levada ao equipamento de FRX (aparelho marca Philips, modelo PW 2400) para realizar a leitura da concentração de todos os elementos presentes nas amostras. 


\subsection{Análise Termogravimétrica e Análise Térmica Diferencial}

Assim, o objetivo desta análise foi verificar a decomposição térmica do catalisador desativado e tratado e avaliar a perda de resistência do material após o processo de remediação.

As análises de TG/DTA foram realizadas no equipamento Mettler Toledo TGA/SDTA851 do Laboratório de Análises de Minerais e Rochas da UFPR. As amostras (30 a $50 \mathrm{mg}$ ), colocadas em cadinho aberto de alumina, foram aquecidas de 30 a $700{ }^{\circ} \mathrm{C}$ em atmosfera de nitrogênio (100 mL/min), com rampa de temperatura de $20{ }^{\circ} \mathrm{C} / \mathrm{min}$ e em seguida aquecidas de $700{ }^{\circ} \mathrm{C}$ a $1200{ }^{\circ} \mathrm{C}$ também em atmosfera de nitrogênio, com rampa de temperatura de $5^{\circ} \mathrm{C} / \mathrm{min}$.

\section{RESULTADOS E DISCUSSÃO}

\subsection{Análise de Metais}

A Tabela 1 apresenta os resultados de FRX para os catalisadores antes e após o tratamento.

Tabela 1 - Resultado de FRX para o catalisador desativado e remediado

\begin{tabular}{|c|c|c|c|c|c|}
\hline Substância & Desativado & $\begin{array}{c}\text { Remediado com } \\
\text { ácido sulfúrico }\end{array}$ & $\begin{array}{c}\text { \% removida } \\
\text { com ácido } \\
\text { sulfúrico }\end{array}$ & $\begin{array}{c}\text { Remediado com } \\
\text { citrato de sódio }\end{array}$ & $\begin{array}{c}\text { \% removida com } \\
\text { citrato de sódio }\end{array}$ \\
\hline $\mathrm{Al}_{2} \mathrm{O}_{3}(\%)$ & $39,300 \pm 5,109$ & $37,700 \pm 4,901$ & 4,07 & $38,900 \pm 5,057$ & 1,02 \\
\hline $\mathrm{SiO}_{2}(\%)$ & $50,600 \pm 6,578$ & $50,000 \pm 6,500$ & 1,19 & $47,700 \pm 6,201$ & 5,73 \\
\hline $\mathrm{Na}(\%)$ & $0,390 \pm 0,051$ & $0,220 \pm 0,029$ & 43,59 & $0,800 \pm 0,104$ & 105,13 \\
\hline $\mathrm{P}_{2} \mathrm{O}_{5}(\%)$ & $1,160 \pm 0,151$ & $0,400 \pm 0,052$ & 65,52 & $1,085 \pm 0,141$ & 6,47 \\
\hline $\mathrm{Fe}(\%)$ & $0,770 \pm 0,100$ & $0,490 \pm 0,064$ & 36,36 & $0,560 \pm 0,073$ & 27,27 \\
\hline $\mathrm{Ni}(\%)$ & $0,284 \pm 0,037$ & $0,280 \pm 0,036$ & 1,44 & $0,278 \pm 0,036$ & 2,320 \\
\hline $\mathrm{V}(\%)$ & $0,200 \pm 0,026$ & $0,152 \pm 0,020$ & 24,09 & $0,142 \pm 0,018$ & 29,19 \\
\hline
\end{tabular}

Verifica-se pelos dados apresentados na Tabela 1 que houve uma remoção de óxidos de alumínio e silício em ambos os processos de remediação, o que pode comprometer a estabilidade térmica do material, uma vez que estes óxidos fazem parte da estrutura da zeólita que compõe o catalisador.

Com relação ao sódio (Na) presente no catalisador desativado, o experimento com ácido sulfúrico promoveu uma remoção de $43,59 \%$ deste elemento, enquanto o experimento com citrato de sódio promoveu o aumento de aproximadamente $105 \%$ em seu teor. Isto provavelmente se deve ao citrato de sódio utilizado na remediação e que não foi totalmente removido pela lavagem com água. Como o sódio pode desativar a zeólita e reduzir a octanagem da gasolina, se faz necessário controlar sua presença no catalisador no caso de uma reutilização deste material para catálise.

Verificou-se também a grande remoção de pentóxido de fósforo com a remediação ácida 
$(65,52 \%)$. O teor de ferro diminuiu com os dois tratamentos. Para um dos metais de interesse, o vanádio, ocorreu a remoção de 24,09\% com a remediação ácida e de 29,19\% para a remediação alcalina. Verifica-se então que as quantidades de vanádio removidas pelos dois experimentos são próximas, ou seja, a remediação com citrato de sódio removeu uma quantidade levemente maior de vanádio em um meio menos agressivo.

Para o outro metal de interesse, o níquel, houve pouca remoção para os dois tratamentos, variando em 1,44\% para a remediação ácida e 2,32\% para a remediação alcalina. Conforme citado por Pinto et al (2010) a mobilidade de metal no catalisador é uma característica muito importante, sendo que níquel mostra menos mobilidade do que o vanádio e mantém-se localizado no mesmo ambiente químico.

\subsection{Análise Termogravimétrica e Análise Térmica Diferencial}

Conforme descrito no item de metodologia, as análises de $T G$ e DTA visaram avaliar a decomposição térmica do catalisador desativado e remediado e avaliar a fragilidade do material após o processo de remediação com relação ao aquecimento.

As Figuras 2, 3 e 4 apresentam as curvas TG/DTA para o catalisador desativado, remediado com ácido sulfúrico e remediado com citrato de sódio, respectivamente.

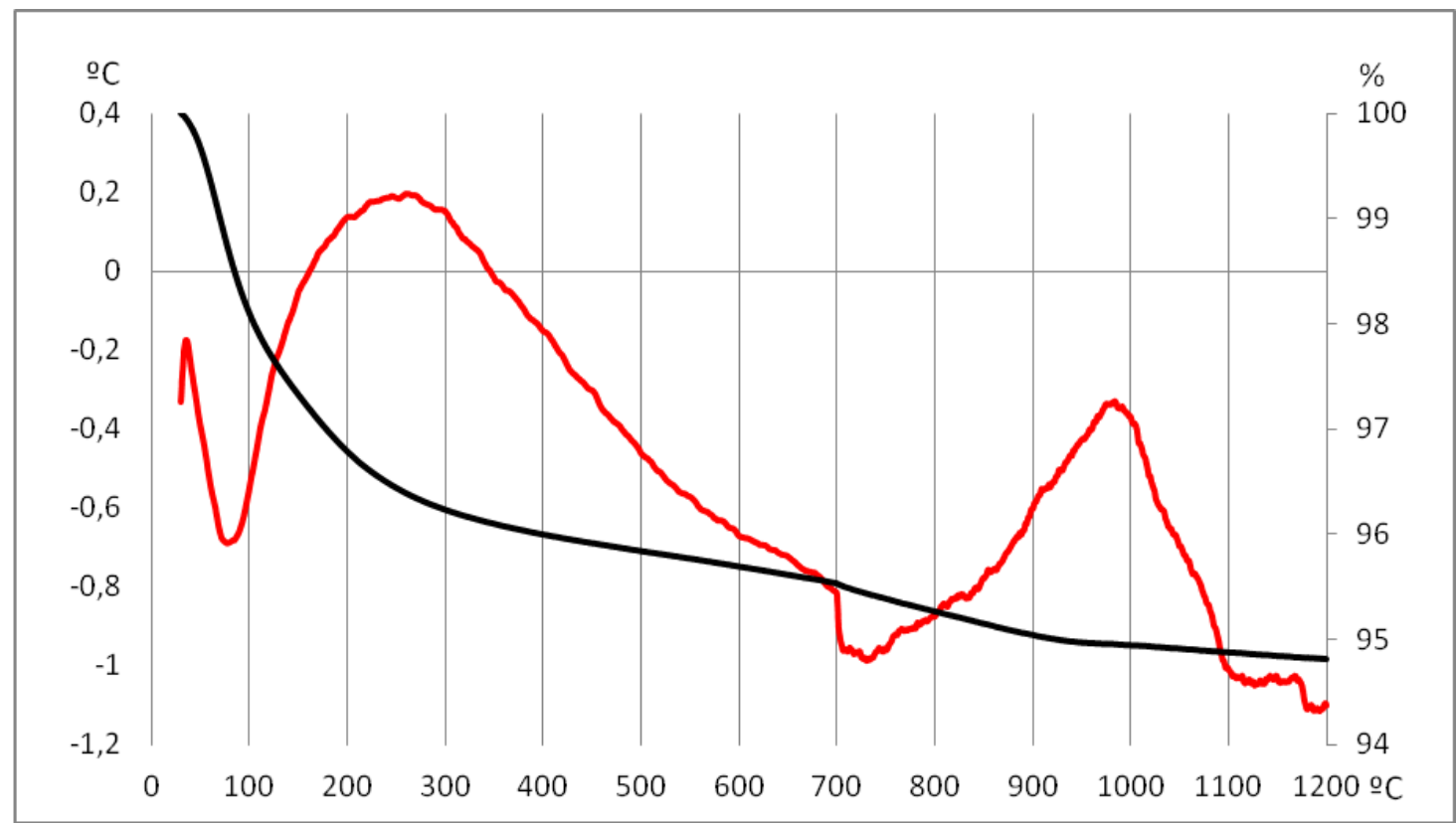

Figura 2 - Curvas de $T G$ (em preto) e DTA (em vermelho) para o catalisador desativado. 


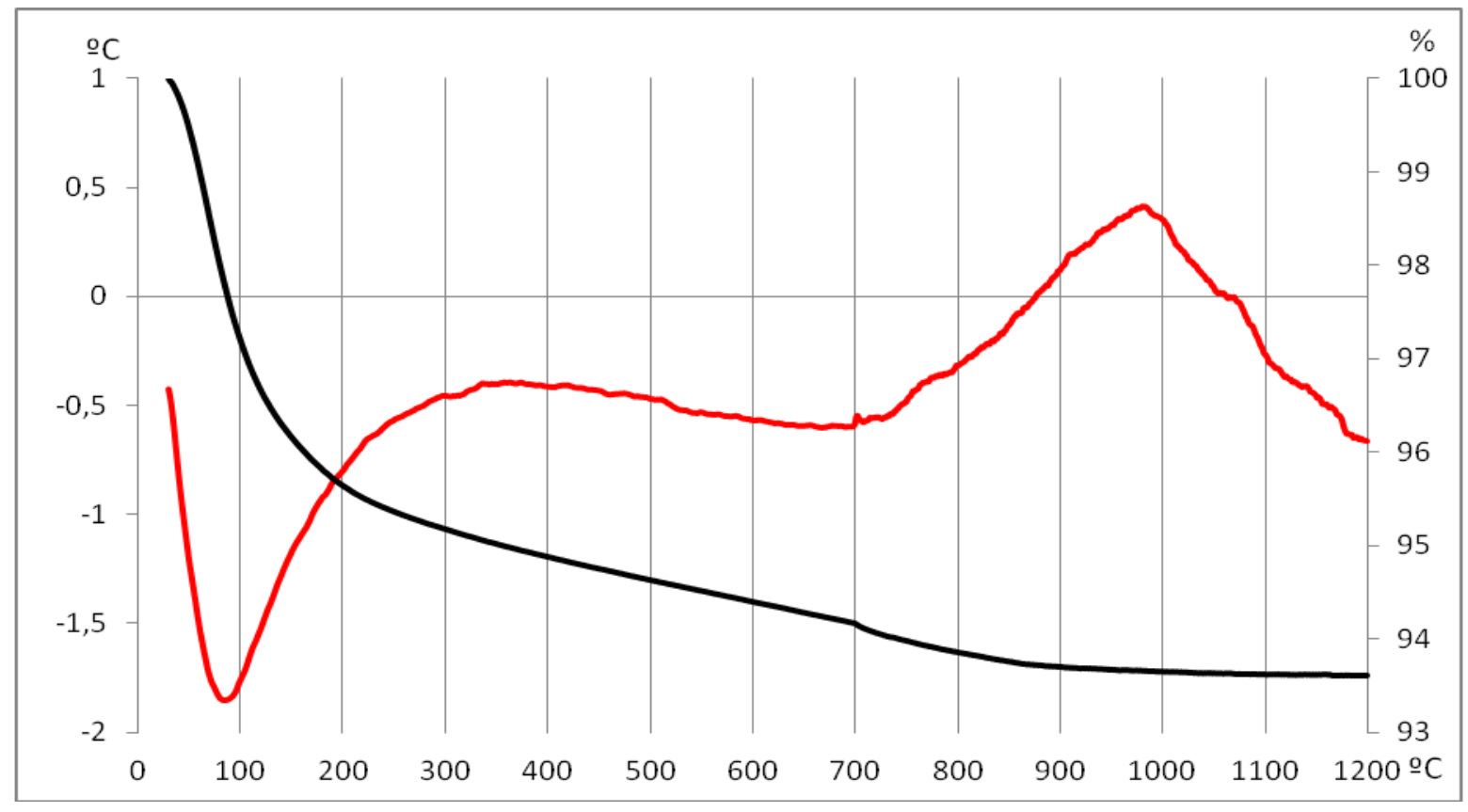

Figura 3 - Curvas de $T G$ (em preto) e DTA (em vermelho) para o catalisador remediado com ácido sulfúrico.

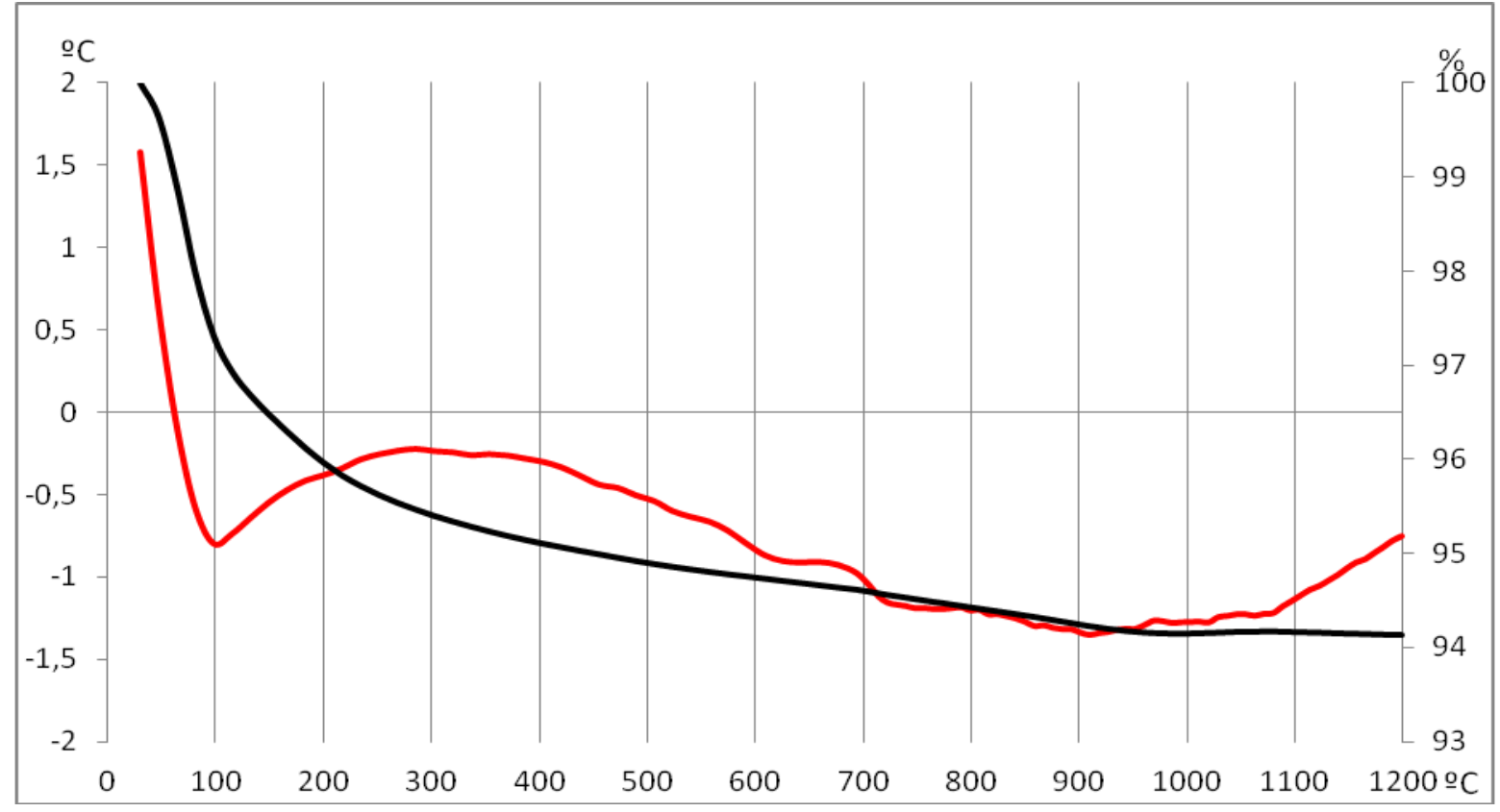

Figura 4 - Curvas de $T G$ (em preto) e DTA (em vermelho) para o catalisador remediado com citrato de sódio. 
O resultado das curvas de TG/DTA indica um percentual de perda de massa das amostras de 5 a 6,5\% relativo à presença de coque de processo e umidade remanescente do tratamento de remediação. No caso da remediação com citrato de sódio existe ainda um percentual de perda de massa relativo à presença de eletrólito que não foi totalmente removido.

O resultado das curvas de TG/DTA indica ainda a ocorrência de dois eventos, um sinal endotérmico com dois picos de temperatura e um sinal exotérmico com um pico de temperatura. Nas Figuras 2, 3 e 4 o primeiro 'pico endotérmico ocorreu em $85^{\circ} \mathrm{C}$ para as três amostras e é atribuído à perda de moléculas de água localizadas nas cavidades da zeólita ou outras espécies voláteis que possam estar presentes.

Um segundo pico endotérmico de característica ampla e não muito bem definido é mencionado pela literatura (Trigueiro et al., 2002) entre 300 e $800^{\circ} \mathrm{C}$, usualmente relacionado à perda de grupos hidroxila que compõe a estrutura da zeólita. Para as amostras analisadas, ele ocorreu em $720^{\circ} \mathrm{C}$ para o catalisador desativado, $715^{\circ} \mathrm{C}$ para o catalisador remediado com ácido sulfúrico e $625^{\circ} \mathrm{C}$ para o catalisador remediado com citrato de sódio.

Um terceiro pico, desta vez exotérmico e localizado entre 1000 e $1150{ }^{\circ} \mathrm{C}$ (Gonçalves et al., 2010), é atribuído ao colapso da estrutura da zeólita ou a uma reestruturação em uma nova fase, e serve como uma medida da estabilidade térmica da zeólita. Para o material desativado este pico ocorreu em $967^{\circ} \mathrm{C}$, enquanto para o material remediado com ácido sulfúrico ocorreu em $984^{\circ} \mathrm{C}$. Para o material remediado com citrato de sódio não foi observado este pico no intervalo esperado, fato que talvez tenha relação com a diminuição da razão Si/Al observado neste tratamento em comparação ao catalisador desativado e que deve ser investigado, uma vez que esta razão $\mathrm{Si} / \mathrm{Al}$ é fundamental para as propriedades da zeólita e seu desempenho catalítico (Cruciani, 2006).

Observou-se a mesma tendência entre as curvas dos catalisadores remediados, apesar de haver diferenças entre as quantidades de energia envolvidas, que serão investigadas em trabalhos futuros.

\section{CONCLUSÃO}

Neste trabalho foi avaliada a estabilidade térmica dos catalisadores de $F C C$ remediados com ácido sulfúrico e citrato de sódio. Verificou-se uma pequena variação nas quantidades de alumínio e silício nos materiais remediados, que podem comprometer a estrutura da zeólita presente no catalisador. No entanto, a análise térmica diferencial mostrou que a remediação eletrocinética não afetou a estabilidade térmica do material, uma vez que todos os picos característicos do material desativado foram preservados.

Vislumbra-se assim o potencial de aplicação da técnica para a regeneração deste tipo de material sem sua desestruturação. 


\section{BIBLIOGRAFIA}

ACAR, Y. B.; GALE, R. J.; ALSHAWABKEH, A. N.; MARKS, R. E. ; PUPPALA, S.; BRICKA, M.; PARKER, R. Electrokinetic remediation : basics and technology status. Journal of Hazardous Materials, v. 40, n.2, p.117-137, 1995.

BAPTISTA, A. Avaliação do potencial de recuperação de metais de catalisadores equilibrados através da técnica de remediação eletrocinética. (Dissertação de Mestrado). Programa de Pós-Graduação em Engenharia de Materiais e Processos. Universidade Federal do Paraná. 2005.

CREPLIVE, M.. Remoção de vanádio a partir de catalisadores Termodinamicamente estáveis. Dissertação. (Dissertação de Mestrado). Programa de Pós-Graduação em Engenharia de Materiais e Processos. Universidade Federal do Paraná. 2008.

CRUCIANI, G. Zeolites upon heating: Factors governing their thermal stability and structural changes. Journal of Physics and Chemistry of Solids, v. 67, n. 9-10, p. 1973-1994, 2006.

CRUYWAGEN, J. J.; ROHWER, E. A. \& WESSELS, G. F. S. Molybdenum (VI) complex formation -8 . Equilibria and thermodynamic quantities for the reactions with citrate. Polyedron. 14: 3481, 1995.

GONÇALVES, M.L.A; VIEIRA, M.D.; MOTA, D.A.P.; CERQUEIRA, W.P.; TEIXEIRA, A.R.F..Differential thermal analysis of a zeolite Y crystalline structure in a catalyst. $J$ Therm Anal Calorim, published online: 05 January 2010.

PINTO, F.V; ESCOBAR, A.S; OLIVEIRA, B.G; LAM, Y.L; CERQUEIRA, H.S; LOUIS, B; TESSONNIER, J.B.; SU, D.S; PEREIRA, M.M. The effect of alumina on FCC catalyst in the presence of nickel and vanadium. Applied Catalysis A: General 388, 15-21, 2010 .

SANCHES, L.; DOMINGUES, S.; CARUBELLI, A. \& MASCARO, L. Electrodeposition of $\mathrm{Ni}-\mathrm{Mo}$ and Fe-Mo Alloys from Sulfate-Citrate Acid Solutions. Journal Brazilian Chemical Socciety, 2003, n. 14, p. 55. 
TRIGUEIRO, F.E.; MONTEIRO, D.F.J.; ZOTIN, F.M.Z.; AGUIAR, E.F.S. Thermal stability of $\mathrm{Y}$ zeolites containing different rare earth cations. Journal of Alloys and Compounds, n. 344,2002 , p. 337-341. 